\title{
Reflections and Provocations
}

Debbie Hohaia
$\begin{gathered}\text { Lisa Hall } \\ \text { Policy, Charles Darwin University } \\ \text { debbie.hohaia@cdu.edu.au }\end{gathered}$
$\begin{gathered}\text { Nia Emmanouil } \\ \text { lisa.hall@batchelor.edu.au } \\ \text { Education }\end{gathered}$
Southern Cross University
nia.emmanouil@scu.edu.au

There was a particular instinct that drove us to produce a special issue on decolonising knowledge practices. We thought that by paying close attention to how research is being done by researchers who are working intentionally to subvert some of the dominant Western paradigms and hegemonies, we may gain some insight into what decolonising knowledge practices look and feel like. This original instinct has been well and truly borne out by the wonderful contributions made by the papers in this issue. Each paper holds tremendous value on its own, but collectively, this issue provides us with a better understanding of the requirements and possibilities of doing decolonising knowledge work.

All papers discuss research that was undertaken in the intercultural space between Indigenous and non-Indigenous ontologies and epistemologies. It is perhaps no surprise then that all papers explicitly name the need for decolonising knowledge work to actively challenge and disrupt the Western or dominant power relationships and worldview that so often directs research. In his paper, Stuart Barlo articulates that 'the greatest act of decolonising research starts with the mindset of the individual researcher with the realisation that Indigenous Australia no longer wishes to be studied or seen as requiring someone to lift them up. What is needed is someone to walk beside them as equal partners'. Robyn Ober sought out methodologies that gave her alternatives from following a strictly Western academic approach. She states that as an Aboriginal researcher she is 'trying to expand the space to converse, to explore, to engage with multiple voices, perspectives, ideas, thoughts and truths'. Non-Indigenous researcher, Nia Emmanouil also articulates the need to be conscious and resistant to the ongoing ontological and epistemological dominance of the Western Eurocentric worldview. Lisa Hall describes the need for non-Indigenous researchers to remain conscious and alert to the colonised power relationships and imbalances that exist in research work. Explicitly naming hegemonic issues and making conscious choices to subvert embedded power relations are thus demonstrated as important aspects of the decolonising work being undertaken by these early career researchers.

Relationality emerges as a core research principle for all the contributing authors, although practiced in different ways. As non-Indigenous researchers with ongoing relational entanglements with their respective communities and participants, Sam Osborne and Hall navigate the complexities of ethics and participation, as well as relationships between people and knowledge. Debbie Hohaia and Moana Tane both explore the relational and cultural complexity of being Indigenous researchers working within complex Indigenous knowledge spaces and examined how relationships and relational trust helped them to navigate this. 
Ober and Barlo are bound by deep cultural protocols around relationships that pose both opportunities and challenges for the research work undertaken. Emmanouil's paper goes beyond the notion of human interpersonal relationships and asks powerful questions about our relationships with and relational accountability to Country.

Evident in all the papers is the notion that decolonising research work requires, and can result in, the transformation of both the knowledge and the knowers. Barlo writes openly about how his participants embarked on a process of training him as the researcher, while Hohaia remarks on how she learned to regularly reflect on and critique her own ontological position. Hall reports how collaborative research enabled her and the research participants to discover ways of 'being and doing' that helped everyone develop a better understanding of the differences in how they approached things. Emmanouil reflects on the need for patience and being open to encountering and experiencing 'other' realities. These papers make visible the need for researchers to be willing to undergo ontological and epistemological shifts as instigators and participants of decolonising research. Ober describes this shift within herself as learning to be true and bringing the 'whole self' into the research process, while Tane states simply that the research process itself changed her own knowledge about herself, which is fundamental to broader reaching transformation.

'Language' and 'voice' emerge as other distinctive features of doing decolonising knowledge work. Many of the papers in this issue wrestle with issues related to language and voice. Both Tane and Osborne identify the importance of research participants being able to participate in their own language and note that this requires the researcher to somehow address the depth and nuances of language difference. Such situations require acknowledgement of the fact that there are often no words in English that can accurately convey the meaning and depth of Aboriginal and/or Māori words. The word 'sovereignty' offers one such example. If issues pertaining to language and voice are not satisfactorily addressed in the research methods and methodology, a distinct loss of understanding and the perpetuation of unchecked power relations can occur between the researcher and participants. The need to amplify, privilege and convey accuracy of meaning to the voices of Indigenous participants in decolonising research practice is paramount. Hohaia addresses this in her paper when she highlights the need to 'bring Indigenous voices to the fore' by consciously seeking opportunities in the research process to 'open dialogue', for deeper understanding. However, despite best efforts to reduce the colonial impact, she finds the dominance of standard forms of English in academia and Western institutions to be a colonising imposition and limitation. Hall also encounters this issue in her research. She countered it somewhat by allowing enough time in the process for the participants to embed their understandings in their first language by explaining and discussing concerns with other language speakers. Ober identifies language as central to her research as well noting the importance of having a shared language, Aboriginal English, between her, as researcher, and the participants. Whatever the approach, conscious attention must be paid to the language and voice of participants in decolonising research work.

There are other aspects of decolonising knowledge work that stand out in this collection. For example, Ober, Barlo, Tane and Hohaia all undertook their research with a specific Indigenist focus. Tane asserts the importance of upholding an Indigenous research agenda, while Ober also acknowledges herself as part of a global movement of Indigenist research that is making space for new fresher ways to do research by drawing on traditional knowledge practices. Barlo highlights how Indigenous research can reflect the authority and foundations of Indigenous Knowledge systems. Hohaia reflects upon this within her choice of methodology stating that her research needed to incorporate cosmology, worldview, epistemology and ethical beliefs that were congruous with Indigenous Knowledge systems. The Indigenous researchers writing in this issue explicitly identify the need for the decolonising practices to adhere to and be respectful of the 'ancient protocols' (Barlo) of Indigenous Knowledge systems. 
Exploration of the Insider/Outsider continuum emerges through several of the authors' reflections. Hohaia and Tane both describe their movement between these positions as they navigated their research terrain. Situations in which they were an 'Insider' or 'Outsider' were not always clearly delineated and involved careful and respectful negotiations. Encountering the complexities and power relations deeply embedded in institutions also required careful negotiation. Tane describes her experience of navigating these complex environments as part of a dynamic process of learning and reflecting. Ober and Barlo also confront the task of doing 'Insider' research with Aboriginal people while at times feeling like the 'Outsider' coming from a Western academic research world. Osborne reflects on this theme as someone who is a nonIndigenous Outsider who has overtime become an Insider through the entanglements of family and relationships and through speaking the same language. This dynamic and conscious movement between being an Insider and Outsider plays an important role in decolonising research.

Selecting a methodology was a critical choice made by the authors which informed how they attempted to decolonise their research practice. For most of the authors, their choices supported the development and strengthening of connections: between peoples, peopleplace and people-place-knowledge. Ober explains that her choice of the yarning methodology was made since storytelling, or 'yarning', is embedded within the processes and structure of Aboriginal society. She goes on to explain that stories give us access to layers of deep cultural and historical knowledge. Similarly, Barlo utilised 'yarning' as a methodology that enabled him, as a researcher, to become part of the narrative. Tane, Osborne and Hall gravitated towards storytelling because of its centrality to Indigenous ways of knowing and being and out of a desire to create space of cultural safety for research participants. For these reasons, working with stories emerges as an effective tool for doing decolonising work.

Questions of knowledge ownership and permissions are also central to working with Indigenous people and their knowledges. Barlo raises some vital questions about the ways in which Western academic ethical permissions can often conflict with Indigenous Knowledgebased understandings about access to and ownership of knowledge. Writing in the context of collaborative research, Hall describes the need to build into research ongoing mechanisms to check that the consent given at the beginning of the research continues to feel 'true' and 'right' as the process unfolds. Osborne raises the importance of 'reciprocal obligation - ngapartji ngapartji', emphasising the responsibility of the researchers to ensure that participation in the research is an experience that leaves participants feeling positive. Tane outlines the process she went through to gain permissions for her research by being guided by Cultural Mentors, while both Hohaia and Tane touch on the various ceremonies and cultural protocols they needed to observe above and beyond Western academic ethical consent processes. Finally, both Barlo and Osborne highlight the need to return research work back to community. Questions of permission and ownership of knowledge, data and results will continue to require careful consideration in any decolonising work.

It is our hope that these papers offer the reader an insight into the generative and transformative potential of decolonising research practice. We also hope that emerging (and experienced) scholars will contribute to the ongoing growth of such practices. If this issue offers one encouragement to researchers, it is to explore and name the boundaries and limitations encountered in knowledge production work and to offer these stories as examples of hope. 